\title{
Interleukin-6-174G>C gene promoter polymorphism and prognosis in patients with cancer
}

\author{
Kan Zhai ${ }^{1}$, Yong Yang ${ }^{2}$, Zhi-Gang Gao ${ }^{2}$ and Jie Ding ${ }^{1}$ \\ ${ }^{1}$ Medical Research Center, Beijing Chao-Yang Hospital, Capital Medical University, Beijing 100020, China \\ ${ }^{2}$ Department of General Surgery, Beijing Chao-Yang Hospital, Capital Medical University, Beijing 100020, China \\ Correspondence to: Kan Zhai, email: kan_zhai@sina.com \\ Keywords: Interleukin-6, polymorphism, cancer, prognosis, meta-analysis \\ Received: February 14, $2017 \quad$ Accepted: April 15, $2017 \quad$ Published: May 10, 2017 \\ Copyright: Zhai et al. This is an open-access article distributed under the terms of the Creative Commons Attribution License 3.0 \\ (CC BY 3.0), which permits unrestricted use, distribution, and reproduction in any medium, provided the original author and source \\ are credited.
}

\section{ABSTRACT}

Interleukin-6 (IL-6) is known to be involved in the pathogenesis of cancer progression. IL-6-174G > C polymorphism has shown several results in association studies. In this study, we evaluated the association the IL-6-174G >C polymorphism and overall survival (OS) of cancer using 17 eligible studies with 4,304 patients. Our meta-analysis indicated that IL-6-174G >C polymorphism is not associated with OS when assessed using 3 genotype comparison including GG/(GC+CC), CC/(GC+GG) and CC/GG. Interestingly, compared to GG carrier, patients with IL-6-174GC genotype showed a decreased hazard of poor OS (hazard ratio $=0.81,95 \%$ confidence interval: 0.68-0.96, $P=0.018 ; I^{2}=$ $34.5 \%$, Phet = 0.107). However, for GG/(GC+CC) genotype comparison, this SNP is affect patients' OS obviously in bladder cancer, ovarian and peritoneal cancer, neuroblastoma, gastric cancer and osteosarcoma, though pooled results showing negative association because adverse and protective effect on different type of cancer balance each other. These results suggest IL-6-174G >C polymorphism might play a role in modulating OS in different type of cancer and might contribute to individual treatment in the future.

\section{INTRODUCTION}

The prognosis of cancer is mainly affected by the cancer type, histological characteristics, tumor stage and therapy. Early diagnosis and accurate prognosis prediction is very necessary for cancer patients. Inflammation has a strong association with cancer progression because malignant cells are promoted by the inflammatory cytokines in a microenvironment are to be highly proliferative [1].

In 1985, interleukin-6 (IL-6) was first discovered as a $\mathrm{B}$ cell differentiation factor inducing immature B cells to produce antibody [2]. This cytokine is a general marker of inflammation, which plays pro-inflammatory and anti-inflammatory mediator for its regulating immune response, inflammation and different pathophysiologic process [3-5]. IL-6 is expressed in a diverse range of cell types, for example, B cells, T cells, fibroblasts, macrophages and adipose cells [6]. Several studies show that evaluated IL-6 is associated with many type of tumors such as breast carcinoma, colorectal cancer, lung cancer, ovarian cancer and lymphomas [7-11]. IL-6 could facilitate carcinogenesis through several mechanisms, including apoptosis, survival, proliferation, angiogenesis, invasiveness, metastasis and metabolism [12].

Fishman et al. [13] first reported a single nucleotide polymorphism (SNP) at the promoter region of the IL-6 in 1998. This functional SNP (rs1800795) which is located in -174 is related to the constitutively IL-6 transcription rate, which could control the levels of IL-6. Compared to $-174 \mathrm{CC}$ genotype carriers, $-174 \mathrm{GG} / \mathrm{GC}$ genotype carriers have a higher IL-6 expression [13]. Accumulating evidence has suggested IL-6-174G $>C$ is associated with susceptibility to many types of cancer [14]. Published studies also suggest that this SNP is associated with the prognosis of cancer, including non-small cell lung cancer, bladder cancer, neuroblastoma, breast cancer [15-19]. Although the IL-6-174G $>$ C polymorphism has been 
assessed in association with survival of several types of cancer, the results are still inconsistent.

In the present study, we performed the first comprehensive meta-analysis of available studies to obtain a comprehensive evaluation of the association between IL6-174 polymorphism and cancer prognosis.

\section{RESULTS}

\section{Eligible Studies}

The initial search retrieved 78 studies using different combinations of key words. Fourth-eight studies remained and were obtained in full-text review after deleting duplication. Among them, 4 were excluded for review or other studies except human cancer. Twenty-four were excluded because of no data about IL-174G $>$ C and OS. Two was excluded for retraction. One study [20] was also excluded for plagiarizing others' work [19]. With strict inclusion and exclusion criteria, the primary eligible studies including 17 studies involving a total of 4,304 cancer patients. Table 1 shows the general characteristics of eligible studies. Fifteen studies were conducted on Caucasian [15, $16,18,19,21-31], 1$ were on American [32], and 1 was on Asian [33]. Polymerase chain reaction-restriction fragment length polymorphism (PCR-RFLP), PCR-Sequencing, single-strand conformation polymorphism (SSCP), polymerase chain reaction-sequencing (PCR-sequencing), TaqMan and Sequenom were used.

\section{Overall survival of IL-6-174G $>$ C polymorphism}

The associations between IL-6-174G $>$ C polymorphism and OS of cancer in each eligible studies are shown in Table 2. Because of data quality, we assessed data using several genetic models. Of the combined 9 studies with 2,057 patients, results show that IL6-174GG genotype was not associated with OS compared to $\mathrm{CC}$ and $\mathrm{CG}$ genotype $(\mathrm{HR}=1.15,95 \%$ CI: $0.81-1.64, P=0.436 ; \mathrm{I}^{2}=84.3 \%$, Phet $\left.<0.001\right)$. However, forest plot shows that this SNP is associated with OS with adverse or protective effect on each group, except for breast cancer group (Figure 1). Similar results were also observed in IL6-174CC genotype compared to $\mathrm{GC}$ and $\mathrm{GG}$ genotype including 6 studies with 1,681 patients $\left(\mathrm{HR}=1.19,95 \% \mathrm{CI}: 0.75-1.87, P=0.458 ; \mathrm{I}^{2}=\right.$ $79.6 \%, P$ het $=0.458)($ Figure 2$)$. Five studies comprising of 1,195 patients was analyzed using genotype model GC/GG for an association between IL-6-174 polymorphism and OS. The pooled HR was statistically significant $(\mathrm{HR}=0.81,95 \% \mathrm{CI}$ : 0.68-0.96, $P=0.018$; $\mathrm{I}^{2}=34.5 \%$, Phet $\left.=0.107\right)($ Figure 3$)$.

For $\mathrm{CC} / \mathrm{GG}$ genotype model, no association was found with a total of studies and patients. ( $\mathrm{HR}=1.13$, 95\% CI: $0.86-1.49, P=0.392 ; \mathrm{I}^{2}=14.3 \%$, Phet $=0.360$ ) (Figure 4).

\section{Sensitivity analysis and publication bias}

To evaluate the influence of every study on the pooled HRs in each genetic model, we performed sensitivity analysis. The results indicated that excluding each study did not influence the overall effects, suggesting that this meta-analysis were reliable.

Begg's and Egger's test were performed to evaluate the publication bias of all included studies in each genetic model. The results indicate that no evidence of obvious asymmetry in overall analysis of publication bias for IL-6-174G $>C$ polymorphism in each genetic model (data not shown).

\section{DISCUSSION}

Functional genetic polymorphisms such as SNPs in the promoter potentially affecting expressions of certain genes might be important determinants in malignancies. Accumulating evidences suggest SNPs in IL-6 which is crucial cytokine involved in several cellular pathways may affect survival of cancer. However, the association remains uncertain. Therefore, we performed the first metaanalysis to evaluate IL-6-174G $>\mathrm{C}$ in predicting clinical outcomes of cancer. Our results indicate that there might be a connection between IL-6 polymorphism and OS in patients with cancer. Our study also highlights the effect of constitutively higher IL-6 expression in cancer prognosis.

IL-6 mediates its roles through IL- 6 receptor on the plasma membrane, and this complex along with gp130 and lead to form an activated IL- 6 complex $[34,35]$. This complex exerts its effects activation of several pathways, including MAP kinase, JAK/STAT, PI3K/AKT and NF-B pathways, leading to the transcriptional regulation of key genes in cell survival, proliferation, differentiation, metabolism, angiogenesis, inflammation, invasion, and metastasis [12].

Published studies suggest that evaluated expression of IL- 6 is associated with cancer risk at the time of diagnosis. These results do not contradict that IL-6-174C inducing higher constitutively IL-6 expression associated with increase or decrease survival. Considering heterogeneous malignancies, it's suggested that the level of IL-6 expression might play a different important role at the step of each cancer progression, although the reasons for this have not been understood. For example, studies indicate that IL-6-174G $>\mathrm{C}$ are correlated with altered breast cancer survival of different race and hormone status [36].

The main strength of this meta-analysis was its well defined search strategy and data extraction according to the strict inclusion and exclusion criteria. Because it's difficult to obtain data, there are few studies about IL-6 polymorphism and cancer prognosis. Several genetic models are used in these studies, it's impossible to assess IL-6-174G $>$ C using one genetic model in all included studies. In our study, we calculated the association with this SNP using 4 genotype 
Table 1: Characteristics of eligible studies in this meta-analysis

\begin{tabular}{|c|c|c|c|c|c|}
\hline Study & No. of cases & Country & Ethnicity & Cancer type & $\begin{array}{l}\text { Genotyping } \\
\text { method }\end{array}$ \\
\hline DeMichele et al. (2003) & 124 & America & Caucasian & Breast cancer & PCR-RFLP \\
\hline Hefler et al. (2003) & 120 & Germany & Caucasian & Ovarian cancer & PCR-Sequencing \\
\hline Iacopetta et al. (2004) & 256 & Australia & Caucasian & Breast cancer & PCR-SSCP \\
\hline Leibovici et al. (2005) & 149 & America & Caucasian & Bladder cancer & TaqMan \\
\hline Garg et al. (2006) & 160 & America & Caucasian & $\begin{array}{l}\text { Ovarian and peritoneal } \\
\text { cancer }\end{array}$ & PCR-Sequencing \\
\hline Deans et al. (2007) & 203 & $\begin{array}{l}\text { United } \\
\text { Kingdom }\end{array}$ & Caucasian & $\begin{array}{c}\text { Gastric or oesophageal } \\
\text { cancer }\end{array}$ & TaqMan \\
\hline Wilkening et al. (2008) & 303 & Sweden & Caucasian & Colorectal cancer & TaqMan \\
\hline Cherel et al. (2009) & 293 & France & Caucasian & Breast cancer & PCR-RFLP \\
\hline DeMichele et al. (2009) & 328 & America & Caucasian & Breast cancer & PCR-Sequencing \\
\hline Lagmay et al. (2009) & 96 & America & Caucasian & Neuroblastoma & PCR-RFLP \\
\hline Lopez et al. (2011) & 445 & Brasil & American & Head and neck cancer & TaqMan \\
\hline Totaro et al. (2013) & 326 & Italy & Caucasian & Neuroblastoma & PCR-RFLP \\
\hline Markkula et al. (2014) & 574 & Sweden & Caucasian & Breast cancer & Sequenom \\
\hline Ruzzo et al. (2014) & 161 & Italy & Caucasian & Gastric cancer & PCR-RFLP \\
\hline Gomes et al. (2015) & 434 & Portugal & Caucasian & Non-small cell lung cancer & PCR-RFLP \\
\hline Matsusaka et al. (2016) & 187 & Italy & Caucasian & Colorectal cancer & PCR-Sequencing \\
\hline Qi et al. (2016) & 216 & China & Asian & Osteosarcoma & PCR-RFLP \\
\hline
\end{tabular}

Abbreviations: PCR-RFLP, polymerase chain reaction-restriction fragment length polymorphism; PCR-SSCP, single-strand conformation polymorphism

models and OS of cancer patients. Although 3 of 4 pooled results showing no association with OS, it is affect patients survival evidently, because adverse and protective effect on different type of cancer balances each other. Lippitz and Harris published a review and reported the serum level of IL-6 was significantly associated with survival in $85.6 \%$ of cancer patients $(9917 / 11,583)$ in 23 different types of cancer [37]. They pointed that the evaluated level of IL-6 in serum correlates with survival as paraneoplastic condition in later cancer stages independent of cancer type [37]. Considering IL-6-174G $>$ C could affect the expression of IL-6 protein, independent of cancer type, clinical status of patients included in our meta-analysis could not be uniformed, therefore, we think this might be the reason of negative pooled association using the three genetic models.

There are several limitations in our meta-analysis. First, number of included studies and in this analysis is small. Patterns of genetic models using in published studies are varied. The statistic power of each genetic model was still limited because of the relatively small sample size. Besides genetic polymorphism, other factors, such as tumor microenvironment, therapy and their interaction could contribute to cancer prognosis. For example, in this study, compared to $\mathrm{GC}+\mathrm{CC}$ genotype, $\mathrm{GG}$ carrier is associated with $\mathrm{OS}$ with adverse or protective effect on types of cancer including bladder cancer, ovarian and peritoneal cancer, neuroblastoma, gastric cancer and osteosarcoma, except for breast cancer. It's reported that IL-6 genotype is strongly associated with OS with hormone level [15, 29]. Because of lacking information, the present study did not combine the effects of these multiple factors in the analyses between IL-6 polymorphism and OS. Third, there are several SNPs in IL-6 which reported to be correlated to cancer risk or survival. However, $-174 \mathrm{G}>\mathrm{C}$ is the most famous SNP in IL-6 promoter region which is related to cancer. The present study only assessed $-174 \mathrm{G}>\mathrm{C}$ in the promoter, though it was not possible to analyze all SNPs.

In summary, our results suggest a role for IL6$174 \mathrm{G}>\mathrm{C}$ polymorphism in cancer prognosis. Because of limited number of cases in the present study, further studies are needed to evaluate the significance of these results in each type of cancer in the clinic. 
Table 2: Summary of primary data for association between IL-6-174G $>$ C polymorphism and overall survival of cancer from 17 eligible studies

\begin{tabular}{|c|c|c|c|c|}
\hline \multirow[t]{2}{*}{ Study } & \multicolumn{4}{|c|}{ HR $(95 \%$ CI) } \\
\hline & $\mathrm{GG} /(\mathrm{GC}+\mathrm{CC})$ & $\mathrm{CC} /(\mathbf{G C}+\mathbf{G G})$ & GC/GG & $\mathrm{CC} / \mathrm{GG}$ \\
\hline DeMichele et al. (2003) & $2.60(1.20-5.80)$ & & & \\
\hline Hefler et al. (2003) & & & $0.57(0.27-1.09)$ & $1.58(0.37-6.72)$ \\
\hline Iacopetta et al. (2004) & & $1.99(1.05-3.77)$ & & \\
\hline Leibovici et al. (2005) & $2.46(1.24-4.86)$ & & $0.43(0.18-1.01)$ & $0.42(0.13-1.34)$ \\
\hline Garg et al. (2006) & $0.60(0.38-0.96)$ & & & \\
\hline Deans et al. (2007) & & $1.80(1.20-2.69)$ & & \\
\hline Wilkening et al. (2008) & & & $0.69(0.43-1.10)$ & $1.55(0.88-2.72)$ \\
\hline Cherel et al. (2009) & $0.93(0.51-1.69)$ & $1.07(0.50-2.29)$ & & \\
\hline DeMichele et al. (2009) & $1.09(0.80-1.50)$ & & & \\
\hline Lagmay et al. (2009) & $1.39(1.02-1.92)$ & & & \\
\hline Lopez et al. (2011) & & & $0.96(0.76-1.21)$ & $1.13(0.78-1.64)$ \\
\hline Totaro et al. (2013) & & $1.90(1.05-3.43)$ & & \\
\hline Markkula et al. (2014) & $1.11(0.69-1.77)$ & & & \\
\hline Ruzzo et al. (2014) & $1.69(1.18-2.42)$ & & & \\
\hline Gomes et al. (2015) & & $0.63(0.42-0.94)$ & & \\
\hline Matsusaka et al. (2016) & & $0.70(0.47-1.05)$ & $0.69(0.45-1.04)$ & $0.85(0.38-1.87)$ \\
\hline Qi et al. (2016) & $0.52(0.39-0.68)$ & & & \\
\hline
\end{tabular}

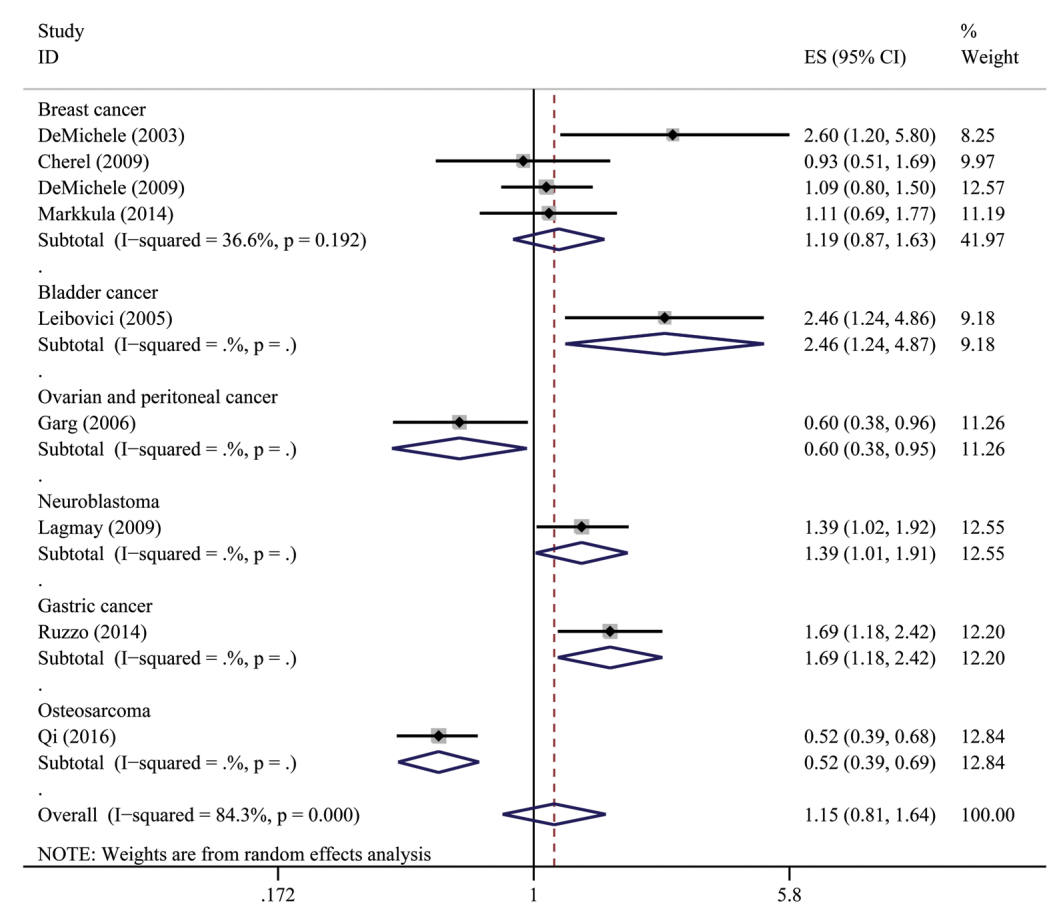

Figure 1: Overall association between IL-6-174G $>$ C polymorphism and OS of cancer (GG/GC+CC). For each study, the estimate of $\mathrm{HR}$ and its $95 \%$ (CI) is plotted with a box and a horizontal line. The symbol diamond indicates pooled $\mathrm{HR}$ and its $95 \% \mathrm{CI}$. 


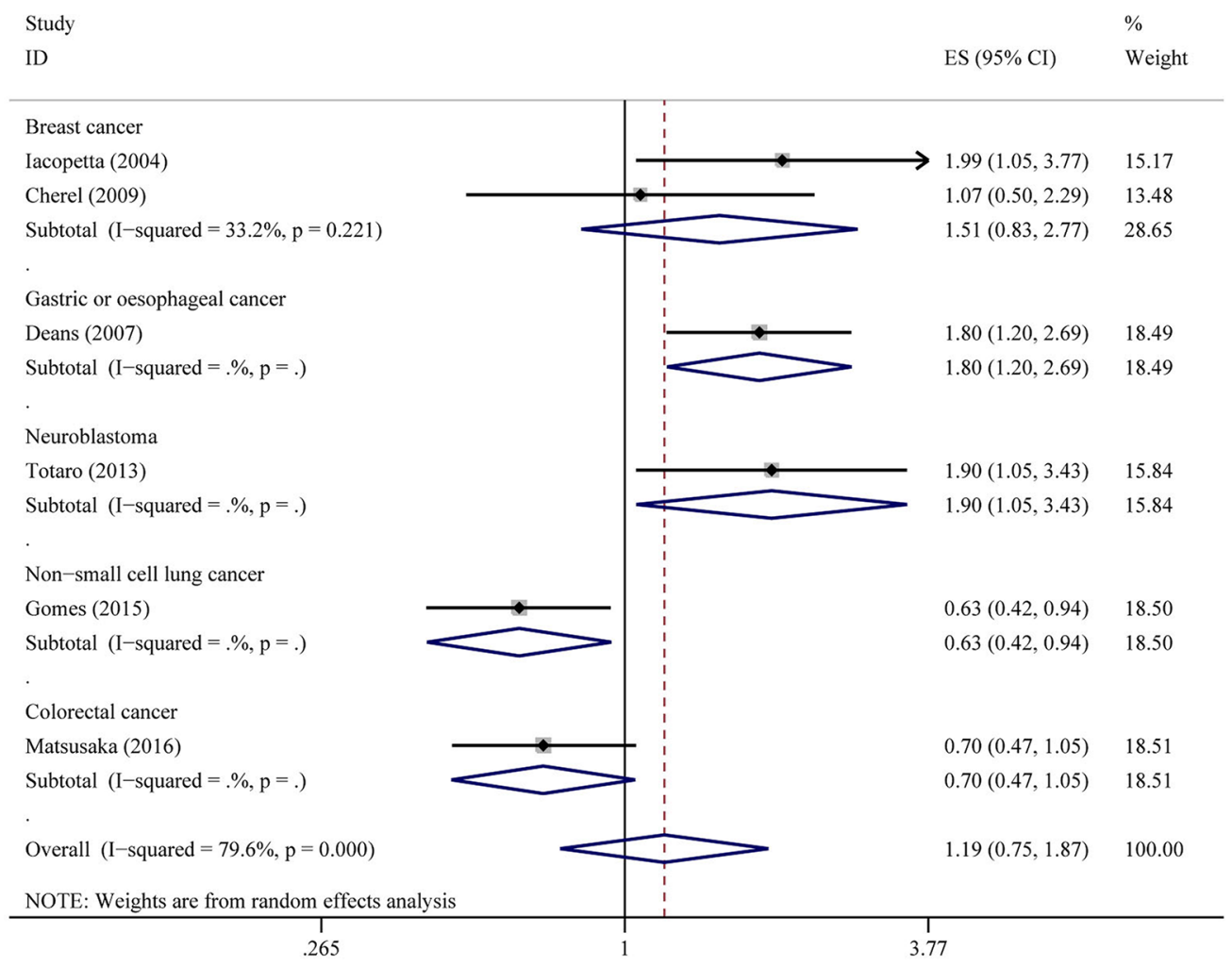

Figure 2: Overall association between IL-6-174G $>$ C polymorphism and OS of cancer (CC/GC+GG). For each study, the estimate of $\mathrm{HR}$ and its $95 \%(\mathrm{CI})$ is plotted with a box and a horizontal line. The symbol diamond indicates pooled $\mathrm{HR}$ and its $95 \% \mathrm{CI}$.

\begin{tabular}{|c|c|c|c|}
\hline \multicolumn{2}{|l|}{ Study } & \multirow[b]{2}{*}{ ES $(95 \% \mathrm{CI})$} & $\%$ \\
\hline ID & & & Weight \\
\hline \multicolumn{4}{|l|}{ Ovarian cancer } \\
\hline Hefler (2003) & & $0.57(0.27,1.09)$ & 6.39 \\
\hline Subtotal $(\mathrm{I}-\mathrm{squared}=. \%, \mathrm{p}=)$. & $\sim$ & $0.57(0.28,1.15)$ & 6.39 \\
\hline \multicolumn{4}{|l|}{ Bladder cancer } \\
\hline Leibovici (2005) & $\leftarrow$ & $0.43(0.18,1.01)$ & 4.19 \\
\hline Subtotal $(\mathrm{I}-\mathrm{squared}=. \%, \mathrm{p}=)$. & 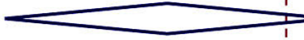 & $0.43(0.18,1.02)$ & 4.19 \\
\hline \multicolumn{4}{|l|}{ Colorectal cancer } \\
\hline Wilkening (2008) & & $0.69(0.43,1.10)$ & 14.11 \\
\hline Matsusaka (2016) & & $0.69(0.45,1.04)$ & 17.74 \\
\hline Subtotal $(\mathrm{I}-\mathrm{squared}=0.0 \%, \mathrm{p}=1.000)$ & & $0.69(0.50,0.94)$ & 31.85 \\
\hline \multicolumn{4}{|l|}{ Head and neck cancer } \\
\hline Lopez (2011) & & $0.96(0.76,1.21)$ & 57.57 \\
\hline Subtotal $(\mathrm{I}-\mathrm{squared}=. \%, \mathrm{p}=)$. & & $0.96(0.76,1.21)$ & 57.57 \\
\hline \multicolumn{4}{|l|}{ Heterogeneneity between groups: $p=0.107$} \\
\hline Overall $(\mathrm{I}-\mathrm{squared}=34.5 \%, \mathrm{p}=0.191)$ & & $0.81(0.68,0.96)$ & 100.00 \\
\hline & $\begin{array}{ll} \\
18\end{array}$ & 56 & \\
\hline
\end{tabular}

Figure 3: Overall association between IL-6-174G>C polymorphism and OS of cancer (GC/GG). For each study, the estimate of $\mathrm{HR}$ and its $95 \%$ (CI) is plotted with a box and a horizontal line. The symbol diamond indicates pooled HR and its $95 \% \mathrm{CI}$. 


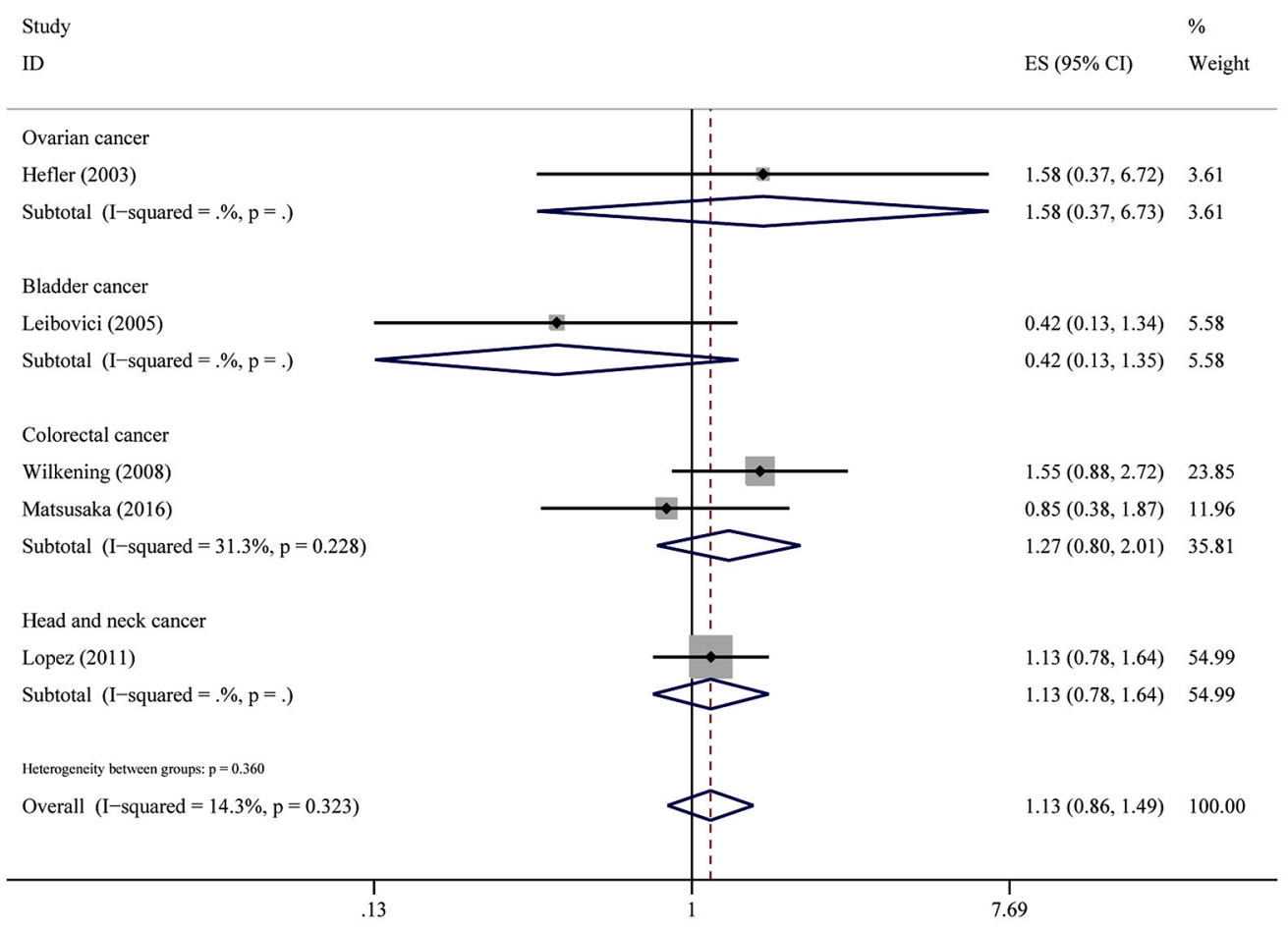

Figure 4: Overall association between IL-6-174G $>$ C polymorphism and OS of cancer (CC/GG). For each study, the estimate of $\mathrm{HR}$ and its $95 \%$ (CI) is plotted with a box and a horizontal line. The symbol diamond indicates pooled $\mathrm{HR}$ and its $95 \% \mathrm{CI}$.

\section{MATERIALS AND METHODS}

\section{Publication Search}

We searched three electronic databases PubMed, Embase and Web of Science up January 2017 for all related studies reporting the genotype of IL-6-174 polymorphism (rs1800795) in cancer patients, using different combinations of the key words 'IL-6 or IL6', '-174', 'rs1800795', 'cancer', and 'survival', without any restriction. The literature search was limited to studies that had been conducted on human subjects. The reference lists of the retrieved articles, reviews and editorials were also screened to find all additional eligible studies.

\section{Inclusion Criteria}

The studies selected had to meet the following criteria: (1) all patients diagnosed with cancer should be histologically confirmed; (2) study evaluated of the IL6-174 polymorphism in patients with cancer and overall survival (OS); (3) published in English; (4) subjects were limited to adult and without autoimmune diseases, studies with children were also excluded; (5) genotyping was based on DNA; (6) sufficient data for estimating hazard ratio (HR) and its corresponding 95\% confidence interval $(95 \% \mathrm{CI})$ for OS. When publications were checked for overlapping patients, only the largest or complete study was selected.

\section{Data extraction}

An initial screening of title and abstract was performed in the first step, followed by further screening based on full-text review. Information was independently collected from all eligible studies by two investigators (K.Z. and Y.Y.), including the first author, publication date, country of the study location, ethnicity of the study population, number of genotyped cases, genotyping method, type of cancer, HR and its $95 \%$ CI for OS. For studies with insufficient information on HRs in primary reports, we extracted data from OS curves. Disagreements were resolved through discussion.

\section{Statistical analysis}

HRs with corresponding 95\% CIs for OS was obtained from each included studies. For studies which data were not directly recorded in primary reports, we calculated HR and their 95\% CIs from survival curves using published method [38, 39]. Kaplan-Meier curves of included studies were read by Engauge Digitizer version 4.1. HR calculation was determined as described in previous published study [40]. Z test was used to determine the pooled HR and $95 \%$ CI. Heterogeneity among studies was examined with $\mathrm{I}^{2}$ statistics. $\mathrm{I}^{2}<50 \%$ indicates no significant heterogeneity between studies, HRs were evaluated using fixed-effect model (MantelHaenszel method). Otherwise, random-effect model 
(DerSimonian-Laird method) was used. The potential publication bias was assessed using Begg's funnel plot and Egger's linear regression test [41, 42]. Sensitivity analyses by excluding every study and recalculating HRs and 95\% CI were conducted [43]. All statistical tests were carried out with Stata 12.0 (StataCorp, College Station, TX, USA). A 2 -tailed $P<0.05$ was considered as statistical significance.

\section{Author contributions}

K.Z. conceived and designed the experiments; K.Z. and Y.Y. performed the experiments. Z.G.G. and J.D. analyzed the data. All authors wrote the paper and approved the final version.

\section{ACKNOWLEDGMENTS}

This work was supported by grants from Beijing Municipal Administration of Hospitals' Youth Programme (QML20150307).

\section{CONFLICTS OF INTEREST}

The authors declare no conflict of interest.

\section{REFERENCES}

1. Grivennikov S, Karin M. Autocrine IL-6 signaling: a key event in tumorigenesis? Cancer Cell. 2008; 13: 7-9.

2. Hirano T, Taga T, Nakano N, Yasukawa K, Kashiwamura S, Shimizu K, Nakajima K, Pyun KH, Kishimoto T. Purification to homogeneity and characterization of human B-cell differentiation factor (BCDF or BSFp-2). Proc Natl Acad Sci U S A. 1985; 82: 5490-5494.

3. Tilg H, Trehu E, Atkins MB, Dinarello CA, Mier JW. Interleukin-6 (IL-6) as an anti-inflammatory cytokine: induction of circulating IL-1 receptor antagonist and soluble tumor necrosis factor receptor p55. Blood. 1994; 83: 113-118.

4. Scheller J, Chalaris A, Schmidt-Arras D, Rose-John S. The pro- and anti-inflammatory properties of the cytokine interleukin-6. Biochim Biophys Acta. 2011; 1813: 878-888.

5. Ishihara K, Hirano T. IL-6 in autoimmune disease and chronic inflammatory proliferative disease. Cytokine Growth Factor Rev. 2002; 13: 357-368.

6. Hirano T. Interleukin 6 and its receptor: ten years later. Int Rev Immunol. 1998; 16: 249-284.

7. Dethlefsen C, Hojfeldt G, Hojman P. The role of intratumoral and systemic IL-6 in breast cancer. Breast Cancer Res Treat. 2013; 138: 657-664.

8. Waldner MJ, Foersch S, Neurath MF. Interleukin-6--a key regulator of colorectal cancer development. Int J Biol Sci. 2012; 8: 1248-1253.
9. Pine SR, Mechanic LE, Enewold L, Chaturvedi AK, Katki HA, Zheng YL, Bowman ED, Engels EA, Caporaso NE, Harris CC. Increased levels of circulating interleukin 6, interleukin 8, C-reactive protein, and risk of lung cancer. J Natl Cancer Inst. 2011; 103: 1112-1122.

10. Maccio A, Madeddu C. The role of interleukin-6 in the evolution of ovarian cancer: clinical and prognostic implications--a review. J Mol Med (Berl). 2013; 91: 1355-1368.

11. Cozen W, Gill PS, Ingles SA, Masood R, Martinez-Maza O, Cockburn MG, Gauderman WJ, Pike MC, Bernstein L, Nathwani BN, Salam MT, Danley KL, Wang W, et al. IL-6 levels and genotype are associated with risk of young adult Hodgkin lymphoma. Blood. 2004; 103: 3216-3221.

12. Kumari N, Dwarakanath BS, Das A, Bhatt AN. Role of interleukin-6 in cancer progression and therapeutic resistance. Tumour Biol. 2016; 37: 11553-11572.

13. Fishman D, Faulds G, Jeffery R, Mohamed-Ali V, Yudkin JS, Humphries S, Woo P. The effect of novel polymorphisms in the interleukin-6 (IL-6) gene on IL-6 transcription and plasma IL-6 levels, and an association with systemiconset juvenile chronic arthritis. J Clin Invest. 1998; 102: 1369-1376.

14. Xu B, Niu XB, Wang ZD, Cheng W, Tong N, Mi YY, Min ZC, Tao J, Li PC, Zhang W, Wu HF, Zhang ZD, Wang ZJ, et al. IL-6 $-174 \mathrm{G}>\mathrm{C}$ polymorphism and cancer risk: a metaanalysis involving 29,377 cases and 37,739 controls. Mol Biol Rep. 2011; 38: 2589-2596.

15. DeMichele A, Martin AM, Mick R, Gor P, Wray L, KleinCabral M, Athanasiadis G, Colligan T, Stadtmauer E, Weber B. Interleukin-6 -174G-->C polymorphism is associated with improved outcome in high-risk breast cancer. Cancer Res. 2003; 63: 8051-8056.

16. Lagmay JP, London WB, Gross TG, Termuhlen A, Sullivan N, Axel A, Mundy B, Ranalli M, Canner J, McGrady P, Hall B. Prognostic significance of interleukin-6 single nucleotide polymorphism genotypes in neuroblastoma: rs1800795 (promoter) and rs8192284 (receptor). Clin Cancer Res. 2009; 15: 5234-5239.

17. Ahirwar D, Kesarwani P, Manchanda PK, Mandhani A, Mittal RD. Anti- and proinflammatory cytokine gene polymorphism and genetic predisposition: association with smoking, tumor stage and grade, and bacillus CalmetteGuerin immunotherapy in bladder cancer. Cancer Genet Cytogenet. 2008; 184: 1-8.

18. Totaro F, Cimmino F, Pignataro P, Acierno G, De Mariano M, Longo L, Tonini GP, Iolascon A, Capasso M. Impact of interleukin-6 -174 G>C gene promoter polymorphism on neuroblastoma. PLoS One. 2013; 8: e76810.

19. Gomes M, Coelho A, Araujo A, Azevedo A, Teixeira AL, Catarino R, Medeiros R. IL-6 polymorphism in non-small cell lung cancer: a prognostic value? Tumour Biol. 2015; 36: 3679-3684. 
20. Jia W, Fei GH, Hu JG, Hu XW. A study on the effect of IL-6 gene polymorphism on the prognosis of non-small-cell lung cancer. Onco Targets Ther. 2015; 8: 2699-2704.

21. Hefler LA, Grimm C, Ackermann S, Malur S, RadjabiRahat AR, Leodolter S, Beckmann MW, Zeillinger R, Koelbl H, Tempfer CB. An interleukin-6 gene promoter polymorphism influences the biological phenotype of ovarian cancer. Cancer Res. 2003; 63: 3066-3068.

22. Iacopetta B, Grieu F, Joseph D. The -174 G/C gene polymorphism in interleukin-6 is associated with an aggressive breast cancer phenotype. Br J Cancer. 2004; 90: 419-422.

23. Leibovici D, Grossman HB, Dinney CP, Millikan RE, Lerner S, Wang Y, Gu J, Dong Q, Wu X. Polymorphisms in inflammation genes and bladder cancer: From initiation to recurrence, progression, and survival. J Clin Oncol. 2005; 23: 5746-5756.

24. Garg R, Wollan M, Galic V, Garcia R, Goff BA, Gray HJ, Swisher E. Common polymorphism in interleukin 6 influences survival of women with ovarian and peritoneal carcinoma. Gynecol Oncol. 2006; 103: 793-796.

25. Deans C, Rose-Zerilli M, Wigmore S, Ross J, Howell M, Jackson A, Grimble R, Fearon K. Host cytokine genotype is related to adverse prognosis and systemic inflammation in gastro-oesophageal cancer. Annals of Surgical Oncology. 2007; 14: 329-339.

26. Wilkening S, Tavelin B, Canzian F, Enquist K, Palmqvist R, Altieri A, Hallmans G, Hemminki K, Lenner P, Forsti A. Interleukin promoter polymorphisms and prognosis in colorectal cancer. Carcinogenesis. 2008; 29: 1202-1206.

27. Cherel M, Campion L, Bezieau S, Campone M, Charrier J, Gaschet J, Ricolleau G, Gouraud W, Charbonnel C, Jezequel P. Molecular screening of interleukin-6 gene promoter and influence of $-174 \mathrm{G} / \mathrm{C}$ polymorphism on breast cancer. Cytokine. 2009; 47: 214-223.

28. DeMichele A, Gray R, Horn M, Chen J, Aplenc R, Vaughan WP, Tallman MS. Host genetic variants in the interleukin-6 promoter predict poor outcome in patients with estrogen receptor-positive, node-positive breast cancer. Cancer Research. 2009; 69: 4184-4191.

29. Markkula A, Simonsson M, Ingvar C, Rose C, Jernstrom H. IL6 genotype, tumour ER-status, and treatment predicted disease-free survival in a prospective breast cancer cohort. Bmc Cancer. 2014; 14:759.

30. Ruzzo A, Catalano V, Canestrari E, Giacomini E, Santini D, Tonini G, Vincenzi B, Fiorentini G, Magnani M, Graziano F. Genetic modulation of the interleukin 6 (IL6) system in patients with advanced gastric cancer: a background for an alternative target therapy. BMC Cancer. 2014; 14: 357.
31. Matsusaka S, Hanna DL, Cao S, Zhang W, Yang D, Ning Y, Sunakawa Y, Okazaki S, Berger MD, Miyamato Y, Parekh A, Stintzing S, Loupakis F, Lenz HJ. Prognostic Impact of IL6 Genetic Variants in Patients with Metastatic Colorectal Cancer Treated with Bevacizumab-Based Chemotherapy. Clinical Cancer Research. 2016; 22: 3218-3226.

32. Lopez RV, Zago MA, Eluf-Neto J, Curado MP, Daudt AW, da Silva-Junior WA, Zanette DL, Levi JE, de Carvalho MB, Kowalski LP, Abrahao M, de Gois-Filho JF, Boffetta $\mathrm{P}$, Wünsch-Filho V. Education, tobacco smoking, alcohol consumption, and IL-2 and IL-6 gene polymorphisms in the survival of head and neck cancer. Braz J Med Biol Res. 2011; 44: 1006-1012.

33. Qi Y, Zhao C, Li H, Zhang B, Tada K, Abe H, Tada M. Genetic variations in interleukin-6 polymorphism and the association with susceptibility and overall survival of osteosarcoma. Tumor Biology. 2016; 37: 9807-9811.

34. Hibi M, Murakami M, Saito M, Hirano T, Taga T, Kishimoto T. Molecular cloning and expression of an IL-6 signal transducer, gp130. Cell. 1990; 63: 1149-1157.

35. Taga T, Kishimoto T. Gp130 and the interleukin-6 family of cytokines. Annu Rev Immunol. 1997; 15: 797-819.

36. Berger FG. The interleukin-6 gene: a susceptibility factor that may contribute to racial and ethnic disparities in breast cancer mortality. Breast Cancer Res Treat. 2004; 88: 281-285.

37. Lippitz BE, Harris RA. Cytokine patterns in cancer patients: A review of the correlation between interleukin 6 and prognosis. Oncoimmunology. 2016; 5: e1093722.

38. Parmar MK, Torri V, Stewart L. Extracting summary statistics to perform meta-analyses of the published literature for survival endpoints. Stat Med. 1998; 17: 2815-2834.

39. Williamson PR, Smith CT, Hutton JL, Marson AG. Aggregate data meta-analysis with time-to-event outcomes. Stat Med. 2002; 21: 3337-3351.

40. Tierney JF, Stewart LA, Ghersi D, Burdett S, Sydes MR. Practical methods for incorporating summary time-to-event data into meta-analysis. Trials. 2007; 8: 16.

41. Begg CB, Mazumdar M. Operating characteristics of a rank correlation test for publication bias. Biometrics. 1994; 50: 1088-1101.

42. Egger M, Davey Smith G, Schneider M, Minder C. Bias in meta-analysis detected by a simple, graphical test. BMJ. 1997; 315: 629-634.

43. Lau J, Antman EM, Jimenez-Silva J, Kupelnick B, Mosteller F, Chalmers TC. Cumulative meta-analysis of therapeutic trials for myocardial infarction. N Engl J Med. 1992; 327: 248-254. 